\title{
Terpenes of Walsura chrysogyne (Meliaceae)
}

\begin{abstract}
Ten known compounds were isolated from the leaves and barks of Walsura chrysogyne. One of the known compounds which was isolated as crystal was structurally confirmed by X-ray crystallography and named chrysura (5). The stereochemistry of the $(20 \mathrm{R}, 24 \xi 1)$-ocotillone (9) which previously established by chemical methods has been elucidated by interpretation using 1D, 2D NMR and comparison with closely related compounds. Among the isolated compounds, eichlerianic acid (4) and viridiflorol (7) showed the most significant ichthyotoxicity against zebrafish (Danio rerio) with Median Tolerance Limit (TLM) of 6.7 and $15 \mathrm{ppm}$ respectively.
\end{abstract}

Keyword: Walsura chrysogyne; Anti-acetylcholinesterase ichthyotoxicity; Walsura chrysogyne and 20R. 